\title{
Changes in Mesenchymal Cell-Basal Lamina Relationships Preceding Palatal Shelf Reorientation in the Mouse
}

\author{
LINDA L. BRINKLEY \\ Department of Anatomy and Cell Biology, University of Michigan Medical \\ School, Ann Arbor, Michigan 48109
}

\begin{abstract}
Two specific regions of the future nasal and oral epithelial surfaces of the secondary palatal shelves increase in cell density during shelf reorientation. The relationships of mesenchymal cells to the basal lamina underlying these regions were examined and compared to those of cells underlying adjacent regions which did not change in cell density. CD-1 mouse fetuses were obtained on day 13.5 of gestation. Some palatal shelves were excised immediately and fixed for electron microscopy; other heads were partially dissected and incubated for $4 \mathrm{hr}$ prior to fixation. Although shelf movement is detected only after $6 \mathrm{hr}$ incubation, the shorter time period was selected in order to detect events which precede reorientation. Electron micrographs were taken of the epithelial-mesenchymal interface of nasal and oral regions known to increase in epithelial cell density (active segments) and of nasal and oral regions which did not increase (inactive segments). Several measurements were made in a 500-nm-wide zone delimited on photographic prints. Distinct differences in mesenchymal cell configuration were found between nasal and oral regions. Active and inactive segments of each region also differed. A filamentous layer attached to the undersurface of the lamina densa was observed to vary in thickness and character between regions as well. After $4 \mathrm{hr}$ incubation, differences in mesenchymal cell configuration and ultrastructure of the sublaminar zone were apparent between regions. These results suggest that local epithelial-mesenchymal interactions, possibly mediated by the extracellular matrix, precede shelf reorientation. Whether these changes in mesenchymal cell configuration actually reflect mesenchymal cell activities that are necessary for shelf reorientation remains to be elucidated.
\end{abstract}

The cellular and molecular activities which underlie movement of the mammalian secondary palatal shelves from a vertical position on either side of the tongue to a horizontal position above it remain unclear. One hypothesis proposed to explain this morphogenetic event is that shelf remodeling occurs, at least in the posterior three-quarters of the palate, because of expansion of a hyaluronate-rich gel-collagen fiber network within the mesenchymal compartment, which is aided and directed by local increases in epithelial cell density. Such increases would buttress those regions against any herniation from the swelling pressure of the mesenchyme and define the path of least resistance as being away from those regions. They would also apply compressive forces to the gel, thereby enhancing the swelling pres- sure within it (Brinkley, 1980, 1984; Brinkley and Morris-Wiman, 1984).

Shelf movement is accompanied by changes in the distribution of both epithelial and mesenchymal cells. In studies of cell distribution around the epithelial perimeter of the shelf, two segments, one on the nasal surface, the other on the oral, have been shown to increase in cell density and layering concomitant with reorientation (Brinkley, 1984). These changes were not attributable to cell division and occurred relatively rapidly, within $6 \mathrm{hr}$. These results suggest that the activities causing changes in epithelial cell distribution may be local. Within the same time frame, significant changes in mesen-

Received September 5, 1985. Accepted March 27, 1986 
chymal cell distribution have also been observed to occur. Mesenchymal cells have been found to accumulate at the periphery of the mesenchyme underlying those nasal and oral segments of the epithelium which undergo changes in cell density (Brinkley and Bookstein, 1986). Local conditions at these regions of the epithelial-mesenchymal interface may encourage or permit mesenchymal cells to interact with the basal lamina if they are relatively nearby. The mesenchymal cells might then be involved in remodeling the basal lamina to facilitate changes in the architecture of the overlying epithelium, as suggested by Bernfield et al. (1984).

The dynamic process of palatal-shelf reorientation cannot be followed in vivo; thus an organ-culture system which supports shelf reorientation (Lewis et al., 1980) was utilized. The system allows shelf reorientation to occur in partially dissected fetal mouse heads beginning up to $30 \mathrm{hr}$ prior to expected in vivo closure. By using this in vitro method, transient events which may precede shelf reorientation may be identified and investigated. As pronounced changes in cell distribution were observable after $6 \mathrm{hr}$, a shorter incubation period was employed to permit detection of any changes in epithelialmesenchymal relationships that precede reorientation. The relationships of the mesenchymal cells immediately subjacent to the basal lamina in regions of the epithelial-mesenchymal interface of the palatal shelf known to increase in cell density during shelf reorientation were compared to those associated with regions which did not. Measurements were made from electron micrographs taken of these regions. Distinct, quantitative differences in the relationship of mesenchymal cells to the basal lamina were observed between regions that change in epithelial cell density and those that do not.

\section{MATERIALS AND METHODS Animals}

A random-bred CD-1 mouse strain was used. Animals were maintained in quarters with lights off from 2000 to $0630 \mathrm{hr}$ (LD 13.5:10.5) and fed Purina mouse chow and water ad libitum. Fertilization was assumed to occur between midnight and $0200 \mathrm{hr}$ of the morning the vaginal plug was found. Palate closure-that is, shelf reorientation and adhesion-normally occurs by the day 14.5 in these mice.
Pregnant dams were gavaged on days 10.5, 11.5, and 12.5 with $0.5 \mathrm{ml}$ of sterile tap water to serve as normal controls for a subsequent drug study reported in the succeeding paper (Brinkley and Morris-Wiman, 1986). Animals were cervically dislocated on day 13.5 of gestation; and the fetuses, which were approximately $18 \mathrm{hr}$ prior to expected shelf reorientation, were harvested under sterile conditions. Chronological age as a measure of development is imprecise; thus fetuses were staged by both crown-rump length and by a morphological rating based on the developmental state of fore- and hindlimbs, ears, eyelids, and hair follicles using the system of Walker and Crain (1960). Some shelves were dissected out and fixed immediately as described below. Other fetuses were decapitated and the heads were partially dissected, as previously described, by removing the brain and tongue while leaving the maxillary-mandibular relationships intact (Brinkley et al., 1975). The heads were incubated in the culture system described below for $4 \mathrm{hr}$. This period was selected as the result of a pilot study which determined that $4 \mathrm{hr}$ was the shortest incubation period after which ultrastructural differences in mesenchymal cell relationships to the basal lamina were observable. In this stage fetus, no shelf reorientation is detectable until after $6 \mathrm{hr}$ of incubation (Brinkley, 1980). Following the incubation period, the heads were harvested and the shelves were removed and fixed as described below.

\section{Culture methods}

Partially dissected fetal heads were hung in a gassed, circulating culture chamber filled with BGJb medium (GIBCO) with $10 \%$ fetal bovine serum (KC Biologicals), supplemented to a final concentration of $8 \mathrm{mM}$ glutamine and containing $50 \mu \mathrm{g} / \mathrm{ml}$ gentamicin (Schering Corp). The medium was constantly circulated, gassed with $95 \% \mathrm{O}_{2}-5 \% \mathrm{CO}_{2}$ using silicone copolymer hollow-fiber devices to maintain a $\mathrm{pO}_{2}$ of $600 \pm 30$ torr, and kept at $34^{\circ} \mathrm{C}$. The unique combination of a high partial pressure of oxygen in the medium combined with constant medium circulation and local stirring around and within the oral cavity of the partially dissected explants has been shown previously to provide good tissue viability with no unusual areas of necrosis after incubation times of up to $24 \mathrm{hr}$ (Lewis et al., 1980). Specific details of the dissection procedures and culture system are described 
in Brinkley et al. (1975) and Lewis et al. (1980), respectively.

\section{Histological methods}

Shelves were fixed in $2 \%$ glutaraldehyde in $0.1 \mathrm{M}$ phosphate buffer containing $1 \%(\mathrm{w} / \mathrm{v})$ tannic acid (Mallinckrodt) to preserve the glycosaminoglycans and glycoproteins (Singley and Solursh, 1980), rinsed in buffer, and postfixed in $1 \%$ osmium tetroxide in phosphate buffer. Tissues were dehydrated in a graded ethanol series, cleared in propylene oxide, and embedded in Epon. Thick cross sections of the shelf were taken, the appropriate region of the shelf perimeter was selected, and the blocks were trimmed accordingly. Silver-gold sections were then obtained by using a Huxley ultramicrotome and stained with uranyl acetate and lead citrate. Sections were examined and photographed with a Philips 400 electron microscope.

\section{Sampling and data collection}

The secondary palatal shelf is divisible into four anatomically identifiable regions which behave in region-specific manners: anterior, middle, and posterior presumptive hard palate, and presumptive soft palate (Diewert, 1978; Brinkley and Vickerman, 1979, 1982). Pronounced changes in epithelial cell distribution have been observed in the posterior two-thirds of the palatal shelf. Presumptive hard palate composes one-half to two-thirds of this region. Thus, for this study the posterior region was used. Figure 1 illustrates a cross section of the posterior region.

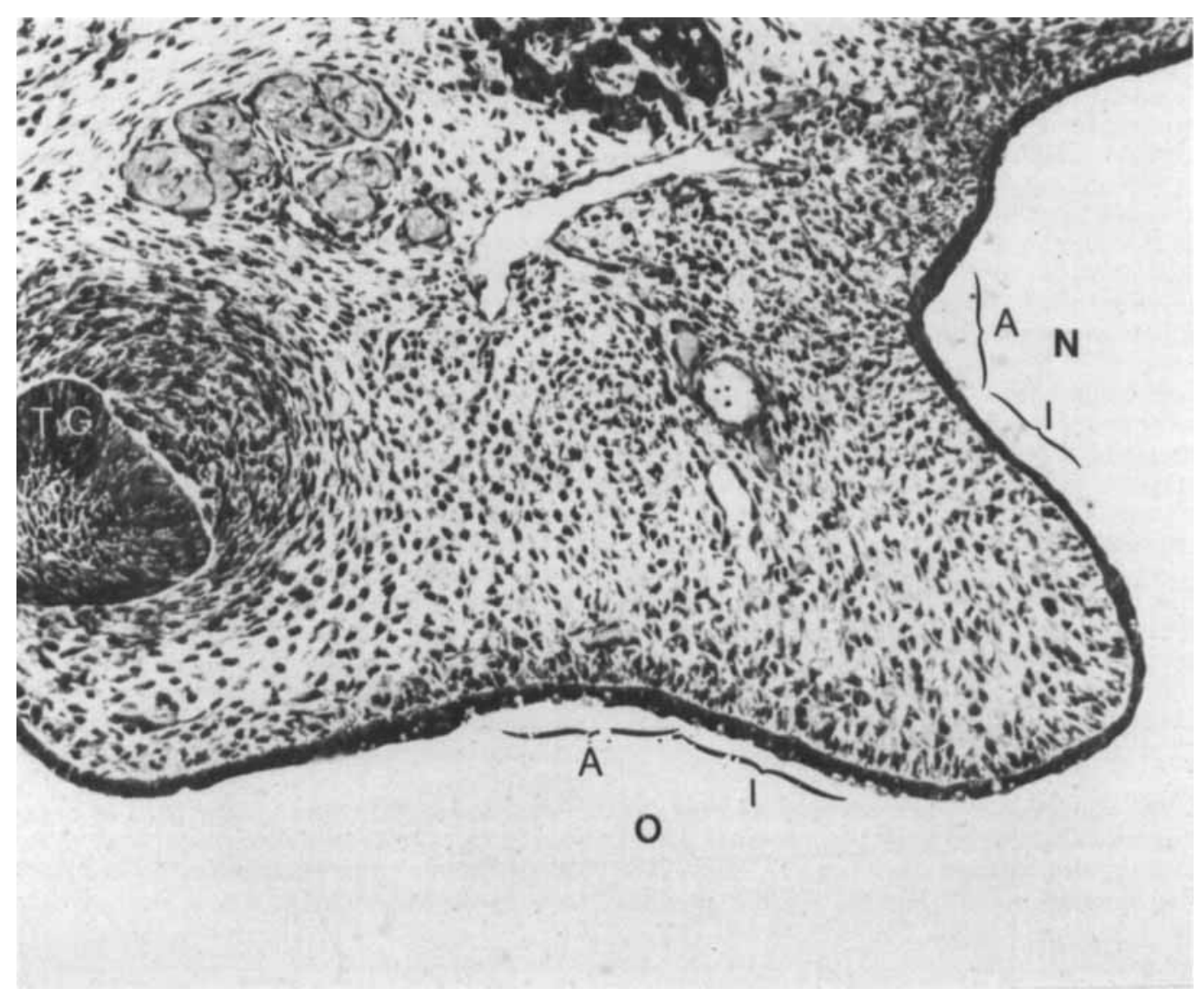

Fig. 1. Cross section of a posterior palatal shelf indicating the nasal $(\mathrm{N})$ and oral $(\mathrm{O})$ regions, and the active (A) and inactive (I) areas based on whether the epithelial cells increase in density or remain the same during shelf reorientation (Brinkley, 1984). TG, tooth germ. $\times 187$. 


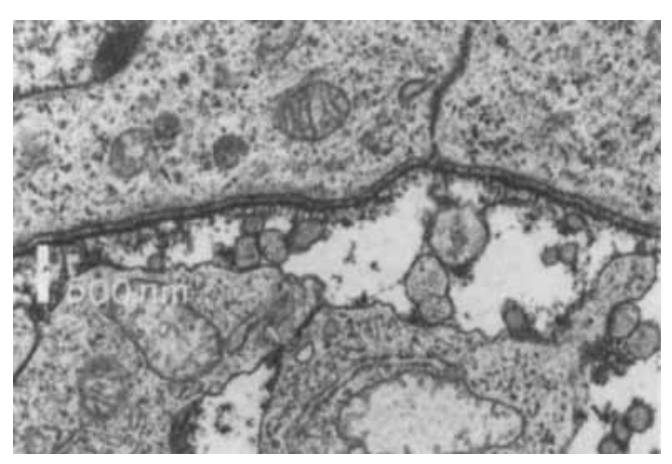

Fig. 2. Low-power electron micrograph of the epithelial-mesenchymal interface indicating the $500-\mathrm{nm}$ measurement zone. $\times 11,960$.

Two to six shelves, each from a different individual, were examined for each region and incubation time. The individuals were taken from two to four different litters. Micrographs of the epithelial-mesenchymal interface underlying 10 to 12 consecutive epithelial cells were taken. Photographs were printed to a final magnification of $\times 27,800$, and a collage of each area was composed. A 500 -nm-wide zone immediately subjacent to the lamina densa was delineated (Fig. 2). The following measurements were made in that zone with the aid of a Summagraphics bitpad linked to a Tektronix 4054 running a simple micrograph measurement program: 1) cross-sectional size of each cell process; 2) cross-sectional area of cell bodies (classified as such by a visible nucleus within the measurement zone); 3) point-to-point distance from the leading edge of each cell process to the lower edge of the lamina densa; 4) run length of the lamina densa; and 5) length of the lamina densa in intimate contact with cell processes (that is, with no visible distance between the process and the lamina).

\section{Data analysis}

The data for cell process size and for the distance from the basal lamina were found to have non-normal distributions. Therefore the nonparametric Kruskal-Wallis median statistical test was employed on these data sets. Because of the variability in numbers of cell processes contacting the basal lamina in each of the four regions examined, sample sizes varied greatly. Because of this, no statistical tests were employed on these data, but rather all the data are presented and trends are discussed.

\section{RESULTS \\ Ultrastructure}

Typical electron micrographs of the nasal and oral region of the epithelial-mesenchymal interface before and after incubation are shown in Figures 3 and 4, respectively.

The typical basal lamina profile seen when tannic acid was used in the fixative was observed in all regions, both before and after incubation. The lamina lucida was traversed by fine filaments with no particular periodicity and the lamina densa was electrondense and compacted. A filamentous layer attached to the undersurface of the lamina densa, which varied greatly in thickness, was also visible. Tannic-acid-precipitable material (TAPM), composed of $\sim 5$-nm filaments and 3- to 5-nm granules, presumably hyaluronate studded with proteoglycan granules (Singley and Solursh, 1981), was observed in all regions, but the amount varied.

Prior to incubation, a pronounced sublaminar filamentous region composed largely of long, 20-nm-thick, unbanded filaments oriented perpendicular to the lamina densa was often seen in many portions of the nasal active (NA) regions (Fig. 3A). These filaments often contacted or even enmeshed nearby cell processes, but sometimes they merely extended into the mesenchyme. At some points the unbanded filaments appeared to traverse the lamina densa and become continuous with the fine filaments within the lamina lucida. Nasal inactive (NI) regions (Fig. 3B) had sparse sublaminar filaments and TAPM, although in some segments somewhat more collagen was seen than was observed in NA regions.

Oral active (OA) regions (Fig. 3C) had many smaller cell processes, but a relatively undeveloped sublaminar filamentous zone. In contrast to the NA regions, few if any $\sim 20-\mathrm{nm}$
Fig. 3. Typical epithelial-mesenchymal interface of nasal active (A), nasal inactive (B), oral active (C), and oral inactive (D) regions prior to incubation. Arrow- heads, $\sim 20$-nm filaments; thin arrows, tannic-acid-precipitable material; open arrows, collagen. A-C, $\times 20,000$; $\mathrm{D}, \times 27,000$. 

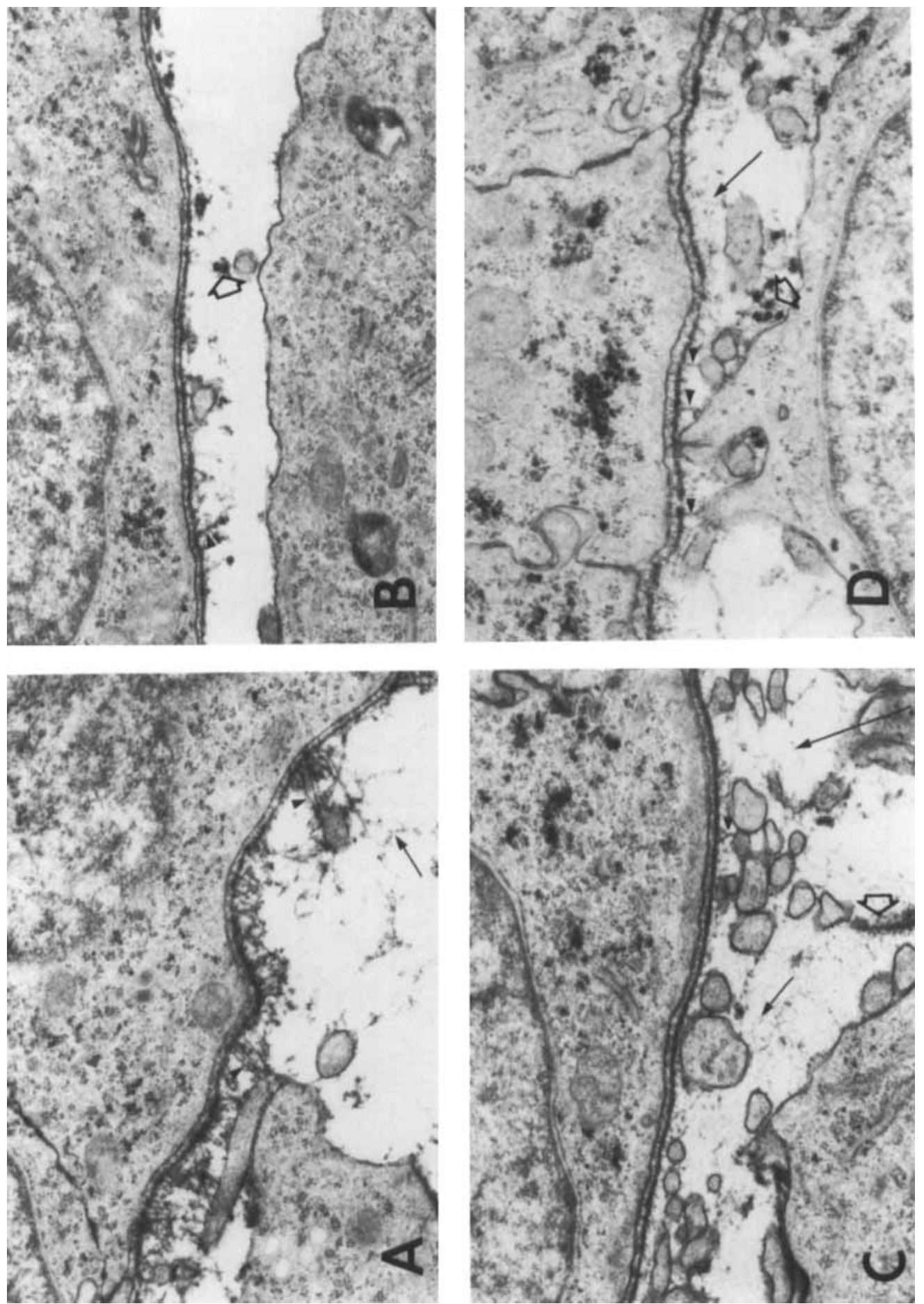

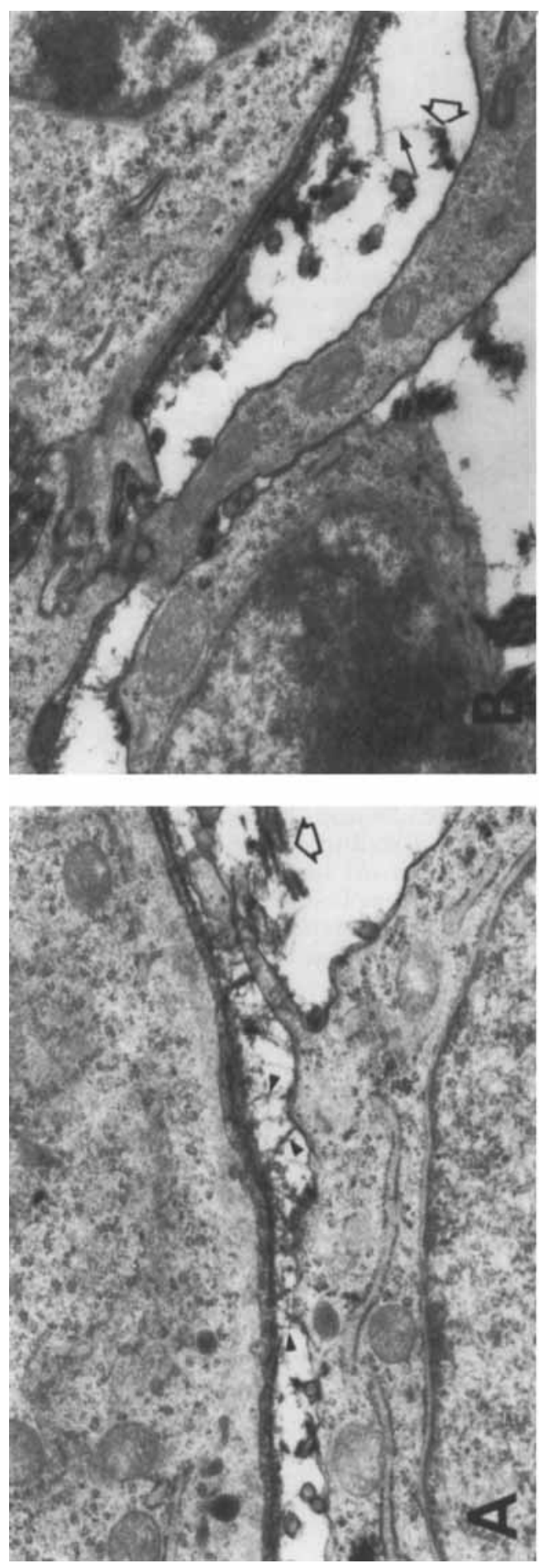
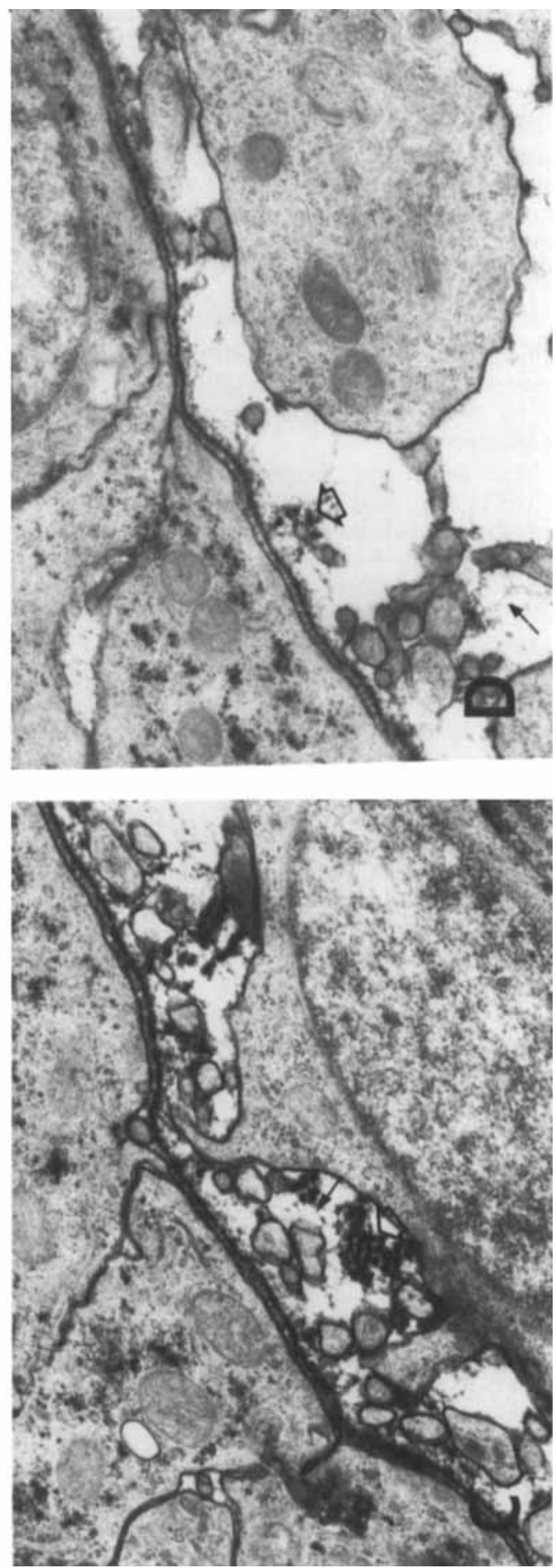
unbanded filaments were seen between the lamina densa and nearby cell processes. More TAPM as well as 20-nm filaments bridging between cell processes and the lamina densa were again observed in the oral inactive (OI) region (Fig. 3D).

After $4 \mathrm{hr}$ incubation, cell processes of the NA regions (Fig. 4A) were now nearer to the lamina densa and were often weil embedded in the TAPM-rich filamentous sublaminar layer. In several regions, direct cell-lamina densa contact with no intervening material was observed. A very pronounced, filamentous layer was also apparent in NI regions (Fig. 4B), which seemed to keep cell processes at a distance from the lamina densa. The OA regions (Fig. 4C) showed increased amounts of filamentous material in the sublaminar layer, and prominent $-20-\mathrm{nm}$ filaments bridging between the lamina densa and cell processes were frequently observed. Cell processes which made direct contact with the lamina densa made rather extensive contact with it. OI regions showed large numbers of small cell processes and a less organized, more flocculent sublaminar layer with few 20-nm filaments.

\section{Cell process number}

There were fewer cell processes per $1 \times 10^{6}$ $\mathrm{nm}^{2}$ in the nasal region than in the oral regions before incubation (Table 1). After 4 $\mathrm{hr}$ incubation, the slight difference seen initially between the number of processes in the $\mathrm{NA}$ and NI regions was no longer apparent. $\mathrm{OA}$ and OI regions now had somewhat fewer cell processes and were also equal. Oral re- gions continued to have more cell processes than nasal ones.

\section{Cell process size}

The size distribution of the cell processes is shown in Figure 5. Prior to incubation ( $0 \mathrm{hr}$ ), the median sizes of cell processes in the nasal regions were significantly larger than those of their counterparts in the oral regions ( $P$ $\leqslant .001$ ). Within regions, however, neither NA and NI nor OA and OI were different from one another.

After $4 \mathrm{hr}$ incubation, median cell-process size of the NA region decreased, while that of the NI remained unchanged. This contrasted with the oral regions, where both $\mathrm{OA}$ and OI showed increased median cell-process size, with that of the OI region increasing more than that of the $\mathrm{OA}$ region. Both active regions, NA and $\mathrm{OA}$, had smaller median values than their inactive counterparts; but only the difference between OA and OI was statistically significant.

\section{Distance of cell processes to the basal lamina.}

Figure 6 displays the distribution of distances from the cell processes to the undersurface of the lamina densa. Cell processes in the nasal regions were farther from the basal lamina than those in the oral regions. Within the nasal region, cell processes in the active area were significantly $(\mathrm{P}=\leqslant .002)$ closer than those in the inactive area. $\mathrm{Me}$ dian distances of OA and OI regions were not different. After incubation, no changes were noted in the nasal regions, whereas the OA region showed a significant increase in dis-

TABLE 1. Cell Processes per $1 \times 10^{6} \mathrm{~nm}^{2}$

\begin{tabular}{lccccc}
\hline \multirow{2}{*}{$\begin{array}{l}\text { Incubation } \\
\text { time (hr) }\end{array}$} & \multicolumn{2}{c}{ Nasal $^{1}$} & & \multicolumn{2}{c}{ Oral $^{1}$} \\
\cline { 2 - 2 } \cline { 5 - 6 } & Active & Inactive & & Active & Inactive \\
\hline 0 & 0.0013 & 0.0016 & & 0.0028 & 0.0027 \\
4 & 0.0018 & 0.0018 & 0.0023 & 0.0023 \\
\hline${ }^{1}$ Values are means for the entire data set. & & &
\end{tabular}

Fig. 4. Epithelial-mesenchymal interfaces of the nasal active (A), nasal inactive (B), oral active (C), and oral inactive (D) regions following $4 \mathrm{hr}$ incubation. Arrow- heads, $\sim 20-\mathrm{nm}$ filaments; thin arrows, tannic-acid precipitable material; open arrows, collagen. $\times 20,000$. 
NA

NI

$\mathrm{OA}$

OI

\section{$0 \mathrm{hrs}$}
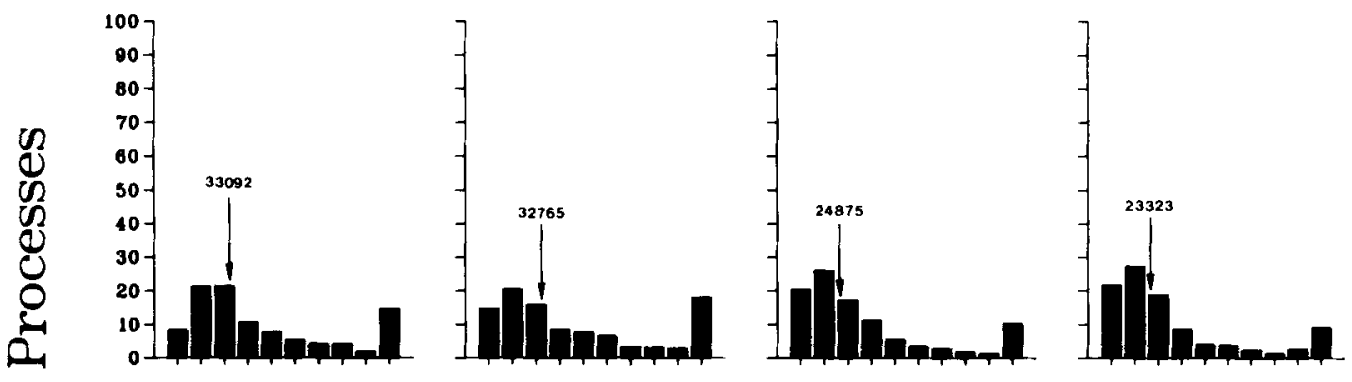

\section{4 hrs}
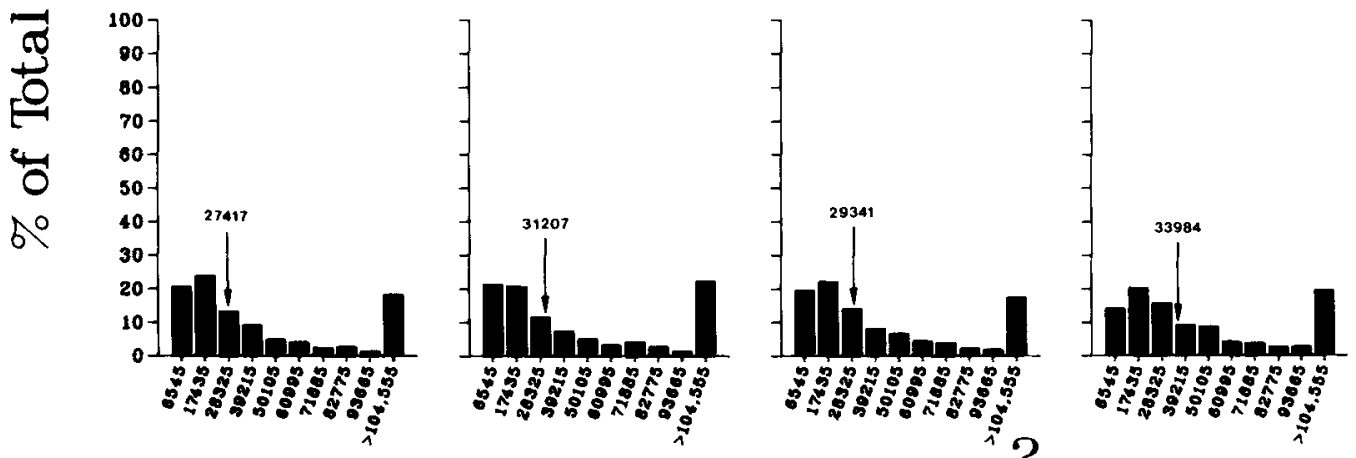

Cell Process Size, $\mathrm{nm}^{2}$

Fig. 5. Distribution of cross-sectional size of mesen- oral inactive. Median values are indicated by the arrows. chymal cell processes at $0 \mathrm{hr}$ and after $4 \mathrm{hr}$ incubation. $\mathrm{NA}$, nasal active; NI, nasal inactive; $\mathrm{OA}$, oral active; $\mathrm{OI}$,

TABLE 2. Proportion of cell processes contacting the basal lamina ${ }^{1}$

\begin{tabular}{llllll}
\hline \multirow{2}{*}{$\begin{array}{l}\text { Incubation } \\
\text { time }(\mathrm{hr})\end{array}$} & \multicolumn{2}{c}{ Nasal (\%) } & & \multicolumn{2}{c}{ Oral (\%) } \\
\cline { 2 - 3 } \cline { 6 - 6 } & Active & Inactive & & Active & Inactive \\
\hline 0 & $23 / 424$ & $4 / 412$ & & $17 / 536$ & $11 / 370$ \\
& $(5.4)$ & $(1)$ & & $(3.2)$ & $(3)$ \\
4 & $16 / 372$ & $5 / 512$ & & $44 / 815$ & $39 / 564$ \\
& $(4.3)$ & $(2)$ & $(5.4)$ & $(6.9)$ \\
\hline
\end{tabular}

${ }^{1}$ No. cell processes contacting basal lamina/total No. of cell processes (\% cell processes making contact).

TABLE 3. \% area covered by cell bodies

\begin{tabular}{lccccc} 
& \multicolumn{4}{c}{ Percentage of: } \\
\cline { 2 - 6 } $\begin{array}{l}\text { Incubation } \\
\text { time (hr) }\end{array}$ & \multicolumn{2}{c}{ Nasal } & & Oral \\
\cline { 2 - 6 } \cline { 2 - 6 } & Active & Inactive & Active & Inactive \\
\hline 0 & 5 & 5 & 8 & 6 \\
4 & 10 & 6 & 6 & 6 \\
\hline
\end{tabular}


tance from the cell processes to the basal lamina.

\section{Cell-process contact with the basal lamina}

The number of cell processes making direct contact with the lamina densa also varied by region and incubation time (Table 2). Initially, cell processes in the NA regions contacted the basal lamina most frequently, while few processes in the NI regions made contact. In $\mathrm{OA}$ and $\mathrm{OI}$ regions, cell processes contacted the basal lamina less frequently than did those in the NA regions but did not differ from them in the amount of contact. After incubation, a greater proportion of the cell processes in all regions except the NA had made laminar contact. The amount of cell-process contact with the lamina densa varied greatly (Fig. 7). Both active regions showed pronounced increases in the contact length per cell process with incubation, while NI showed little increase in contact length.

\section{Proximity of cell bodies to the basal lamina}

The regions varied in the amount of the sublaminar mesenchymal area covered by cell bodies with visible nuclei (Table 3 ). Before incubation, cell bodies occupied the same proportion of both nasal areas, a proportion which was less than that seen in the oral areas. More cell bodies were visible in the oral active areas than in the inactive ones.

After $4 \mathrm{hr}$ in vitro, the amount of space covered by cell bodies had not changed in the two inactive regions but had doubled in the NA area. In contrast, the proportion of space covered by cell bodies decreased in the OA
NA

$0 \mathrm{hrs}$
NI

4 hrs

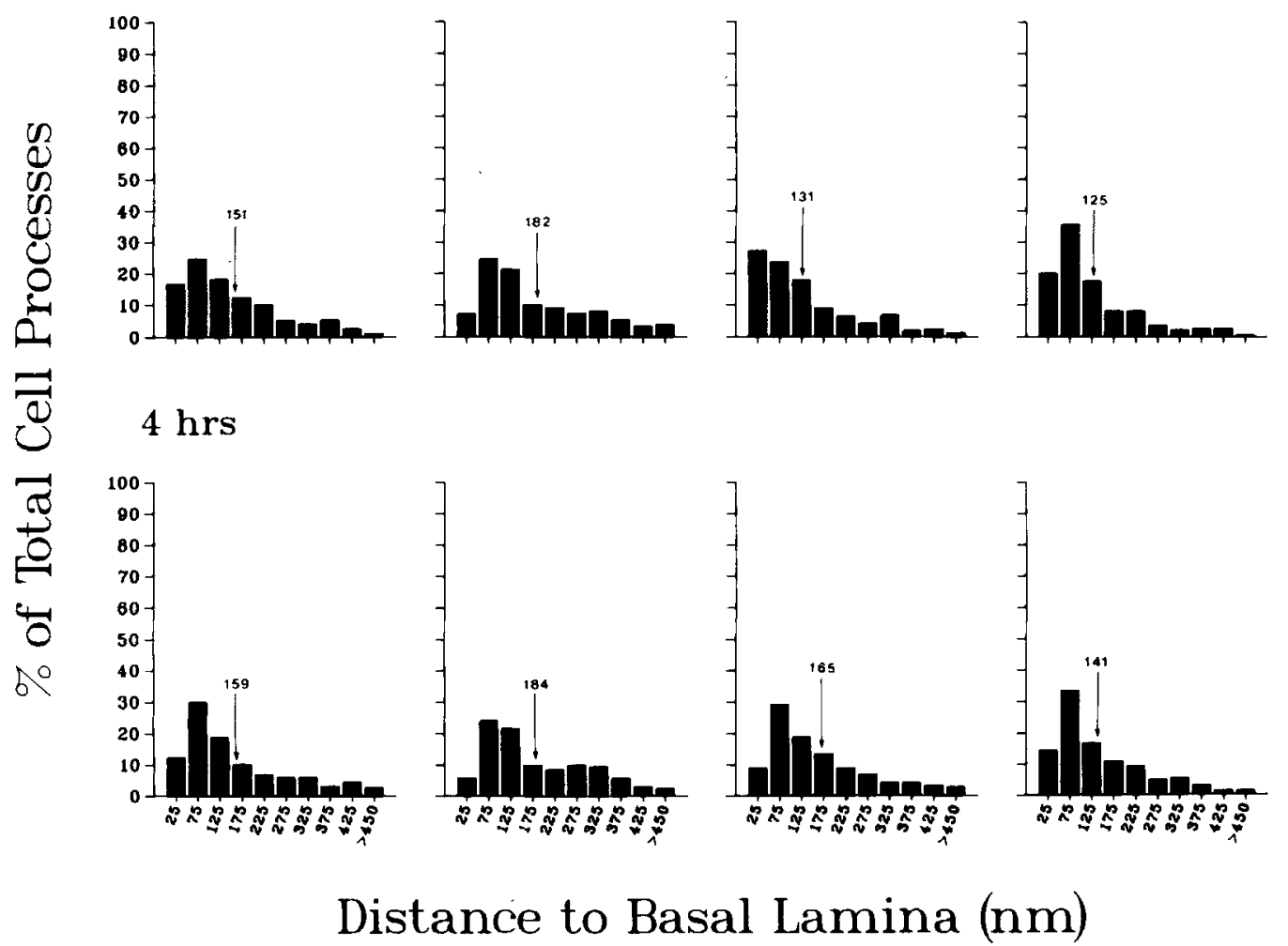

OA
OI

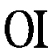

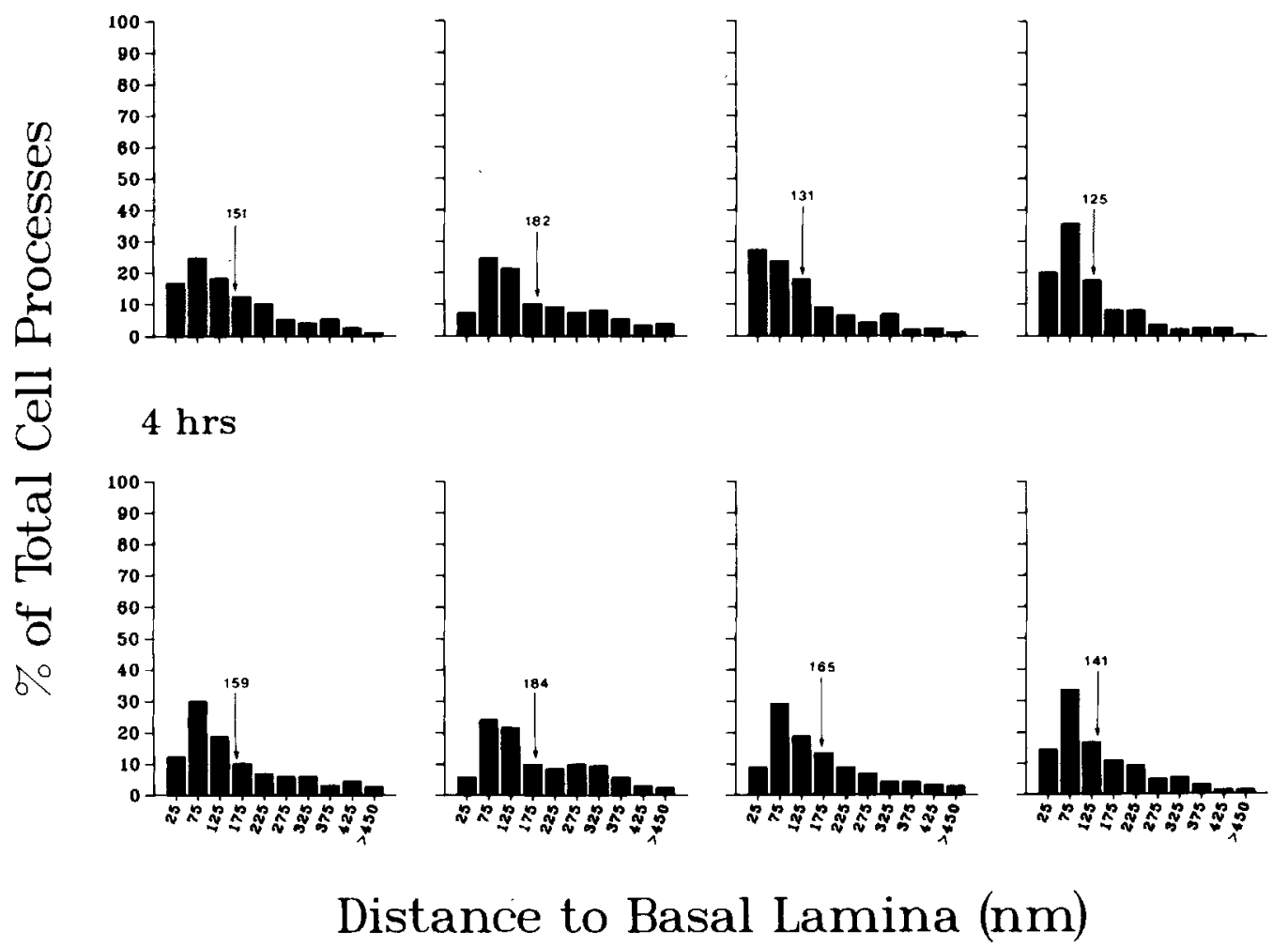
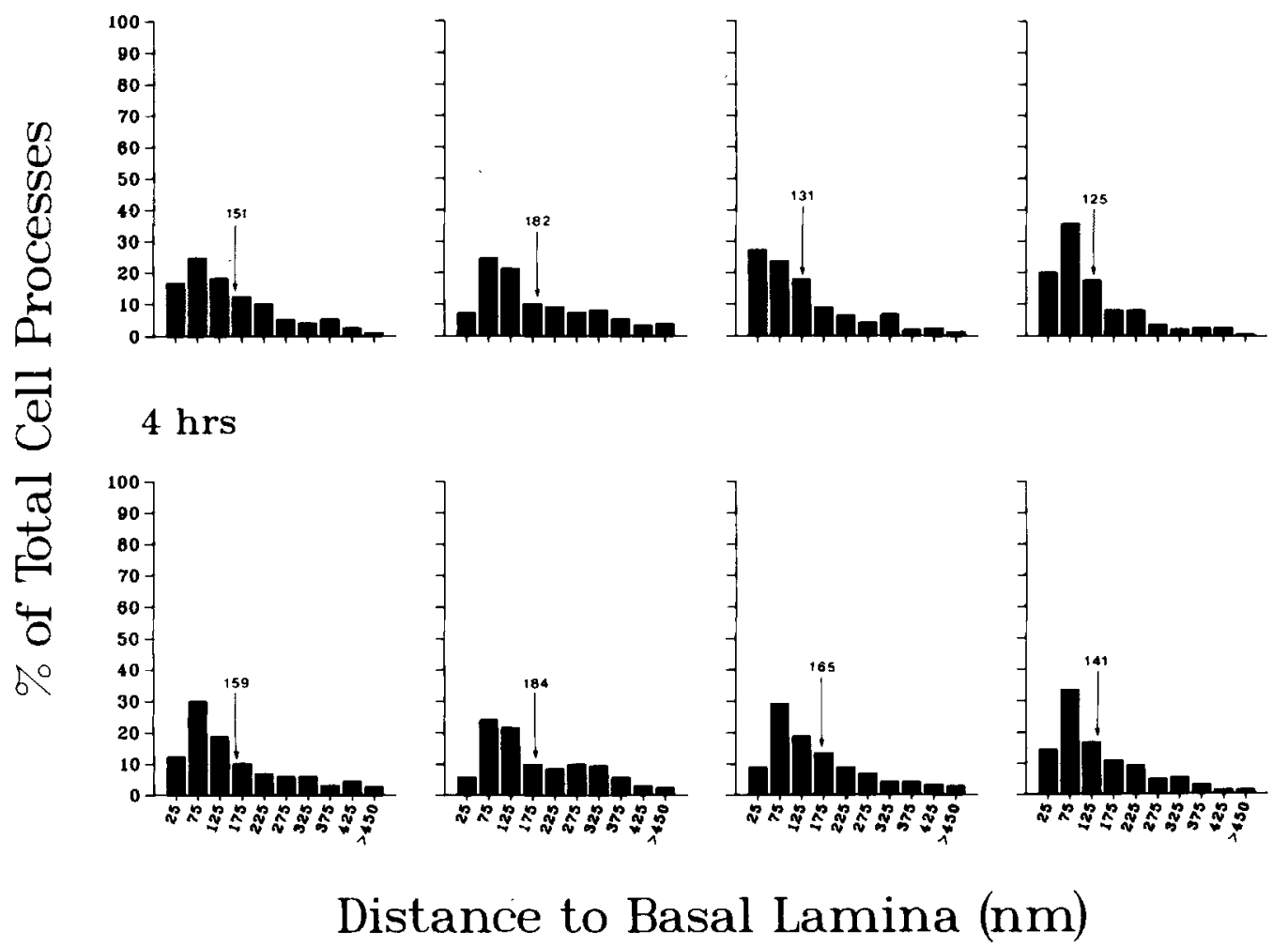

Fig. 6. Distribution of distances from mesenchymal cell processes to the basal lamina. Median values are indicated by arrows. Sample sizes are as given in Table 2 . 
NA

\section{$0 \mathrm{hrs}$}

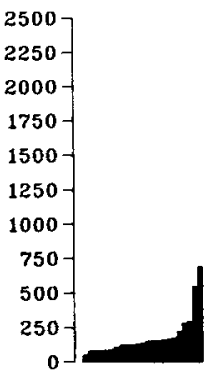

\section{$4 \mathrm{hrs}$}

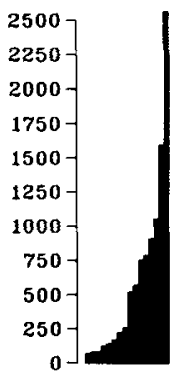

Fig. 7. Extent of contact of each cell process with the lamina densa. Each bar represents the contact made by one cell process. The number of bars shown is the total number of cell processes making direct laminar contact.

region, becoming equivalent to that seen in the two inactive areas.

\section{Changes in mesenchymal cell configurations after incubation}

The changes observed in all measured variables over time are summarized in Table 4. In three of the variables, i.e., number of cell processes per unit area, size of cell processes, and distance to the basal lamina, the nasal and oral regions were different after $4 \mathrm{hr}$ incubation. Within each region, active and inactive areas also differed. In the NA region, more smaller cell processes were observed; the number of processes in contact with the basal lamina decreased, but those that contacted it had more extensive contact
$\mathrm{OA}$

OI
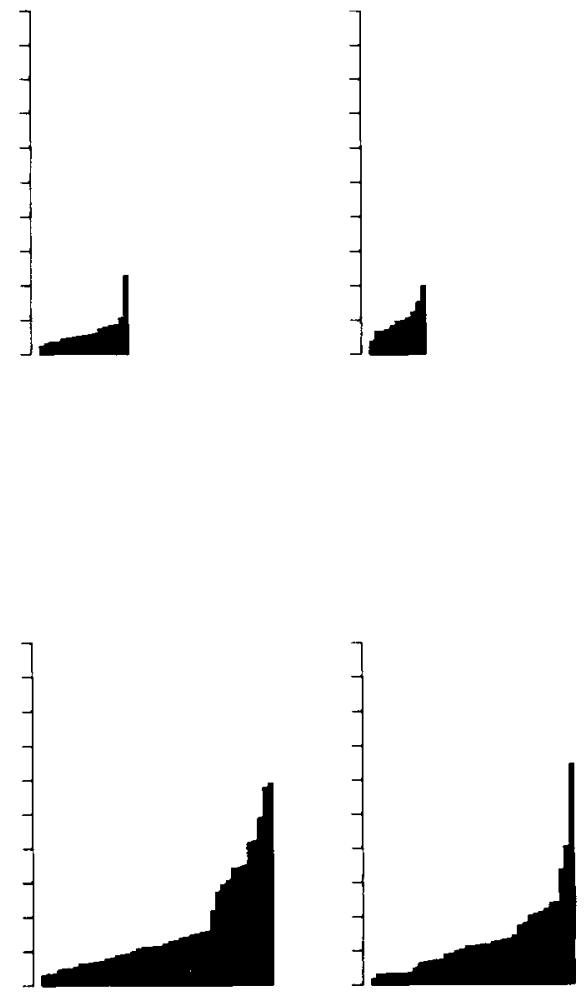

Sample sizes are: $0 \mathrm{hr} ; \mathrm{NA}, \mathrm{n}=23 ; \mathrm{NI}, \mathrm{n}=4 ; \mathrm{OA}, \mathrm{n}=17$; OI, $n=11 ; 4$ hr: NA, $n=16$; NI, $n=5$; OA, $n=44$; OI, $\mathrm{n}=39$.

than seen at $0 \mathrm{hr}$; and more cell bodies had also moved closer to the basal lamina. NI regions showed more cell processes of the same size; more of the cell processes made contact with the basal lamina, and, as in the NA region, more extensive contact was observed. The area covered by cell bodies showed little increase.

In contrast to the nasal regions, the oral regions were characterized by fewer, larger cell processes, particularly in the OI regions. The proportion of processes contacting the basal lamina increased in both oral regions, but the extent of contact increased more noticeably in the OA regions. In both oral regions, cell processes not contacting the basal lamina were now at a greater distance from 


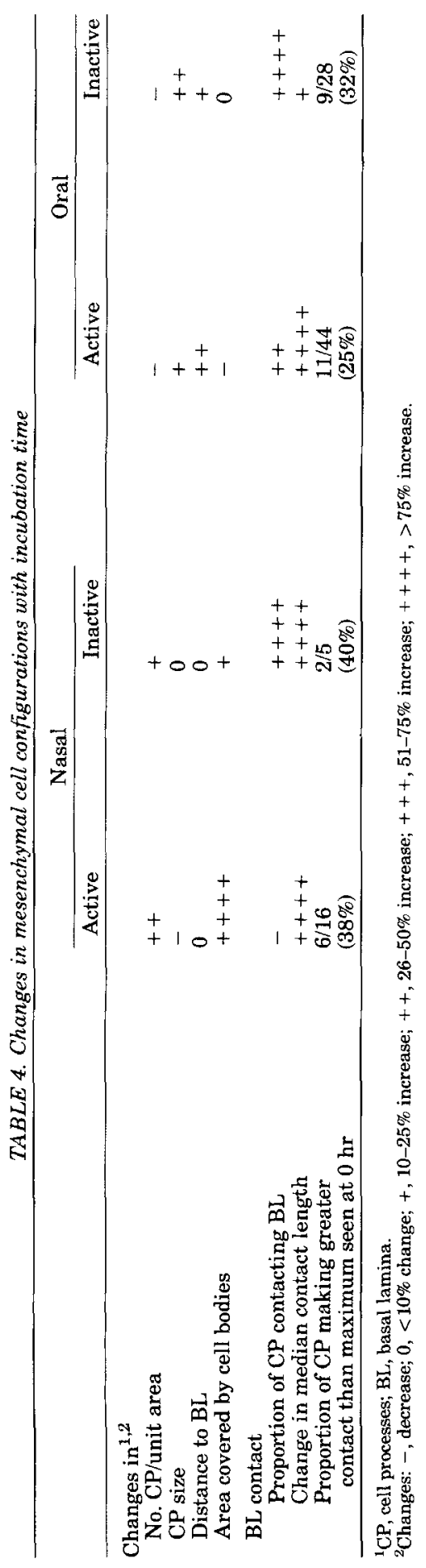

it. The area covered by cell bodies increased in the NA region, decreased in the OA region, and remained essentially the same in both inactive ones.

\section{DISCUSSION}

Quantitative changes in mesenchymal cellbasal lamina relationships which precede in vitro shelf reorientation have been demonstrated in regions of the palatal shelf's perimeter which undergo changes in epithelial cell distribution concomitant with shelf reorientation (Brinkley, 1984). Nasal and oral regions as well as their active and inactive segments were distinguishable from one another by their mesenchymal-cell configurations both before and after incubation. One explanation for these observations is that local differences in the extracellular matrix in the active regions of the epithelial-mesenchymal interface may permit or encourage the particular mesenchymal-cell configurations characteristic of each region. For example, active segments of the nasal regions produce more, smaller cell processes, a larger proportion of which make intimate contact with the lamina densa, than are observed in the inactive segments. The local environment might allow the mesenchymal cells to modify the lamina in such a way that the overlying epithelial cells alter their relationships to one another, resulting in the change in epithelial-cell shape and the increase in cell packing density previously observed (Brinkley, 1984). This suggestion is consistent with the observations of Bernfield et al. (1984) that, in salivary-gland rudiments, mesenchymal cells remodel the basement membrane underlying certain areas of the epithelium, thus changing epithelial-cell architecture which plays a role in generating branching forms.

The ultrastructure of the basal-lamina complex suggests the extracellular matrix associated with the sublaminar areas of these regions of the epithelial perimeter is changing. The filamentous, sublaminar zone immediately subjacent to the lamina densa varies in appearance across regions and with incubation. The $\sim 20$-nm unbanded filaments were initially most prominent in NA and OI regions. Following incubation, all regions displayed them, some more prominently than others. Other investigators have observed similar filaments at the epithelial-mesenchymal interface of other embryonic structures undergoing morphogenetic changes (Kelly and Fallon, 1981; Zimmerman et al., 1985). 
Hurmerinta and Thesleff (1981) reported 10 - to 50-nm nonstriated fibrils associated with and oriented perpendicular to the lamina densa of tooth-germ epithelium. These fibrils increased in density and length during cuspal morphogenesis and were seen to extend to nearby mesenchymal cell surfaces. This agrees with the observations of the present study. Changes in mesenchymal cell alignment were observed to coincide with structural changes in the basement membrane. Slavkin (1974) suggested that such fibrils attract mesenchymal cell processes to specific sites on the basal lamina. These nonbanded fibrils have also been suggested to promote adhesion and orientation of collagen toward the basal lamina (Nadol et al., 1969; Hurmerinta and Thesleff, 1981). The present data sug. gest that could also be the case here. It is clear the fibrils interact with mesenchymal cell processes, attaching to them. However, no specificity of distribution that is consistent with Slavkin's suggestion was observed.

The present data demonstrate that mesenchymal cells, as well as the sublaminar zone of specific areas of the nasal and oral regions of the palatal shelf perimeter, vary in their configurations and relationships to the basal lamina prior to shelf reorientation. These changes may be the result of local, constitutive differences in the basal lamina, in the extracellular matrix of the sublaminar zone, in the pericellular matrix of the mesenchymal cells, or in the state of the mesenchymal cells themselves. The overlying epithelial cells may also be contributing to local environmental differences. Whether, and if so how, the changes in mesenchymal cell configurations identified in the present paper reflect activities which are necessary for shelf reorientation remains to be elucidated.

\section{ACKNOWLEDGMENTS}

This work was supported by NIH-NIDR grants DE02774 and 5K0400104.

\section{LITERATURE CITED}

Bernfield, M., S.D. Banerjee, J.E. Koda, and A.C. Rapraeger 1984 Remodeling of the basement membrane as a mechanism of morphogenetic tissue interaction. In: The Role of Extracellular Matrix in Development. R.L. Trelstad, ed. Alan R. Liss, New York, pp. 545572
Brinkley, L. 1980 In vitro studies of palatal shelf elevation. In: Current Research Trends in Prenatal Craniofacial Development. R.M. Pratt and R.C. Christiansen, eds. Elsevier/North-Holland, New York, pp. 203-220.

Brinkley, L. 1984 Changes in cell distribution during mouse secondary palate closure in vivo and in vitro. I. Epithelial cells. Dev. Biol., 102:216-227.

Brinkley, L., and M. Vickerman 1979 Elevation of le sioned palatal shelves in vitro. J. Embryol. Exp. Morphol., 54:229-240.

Brinkley, L., and M. Vickerman 1982 Effects of chlorcyclizine-induced alterations of glycosaminoglycans on mouse palatal shelf elevation in vivo and in vitro. J. Embryol. Exp. Morphol., 69:193-213.

Brinkley, L., and J. Morris-Wiman 1984 The role of extracellular matrices in palatal shelf closure. In: Current Topics in Developmental Biology, Vol. 19. E.F. Zimmerman, ed. Academic Press, New York, pp. 1736.

Brinkley, L., and F. Bookstein 1986 Cell distribution during mouse secondary palate closure. II. Mesenchy. mal cells. J. Embryol. Exp. Morphol. (in press).

Brinkley, L., and J. Morris-Wiman 1986 The effects of chlorcyclizine-induced glycosaminoglycan alterations on palatal mesenchyme-basal lamina relationships in the mouse. Am. J. Anat., 176:379-389.

Brinkley, L., G. Basehoar, A. Branch, and J. Avery 1975 A new in vitro system for studying secondary palatal development. J. Embryol. Exp. Morphol., 34:485-495. Diewert, V.M. 1978 A quantitative coronal plane evaluation of craniofacial growth and spatial relations during secondary palatal development in the rat. Arch. Oral Biol., 23:607-629.

Hurmerinta, K., and I. Thesleff 1981 Ultrastructure of the epithelial-mesenchymal interface in the mouse tooth germ. J. Craniofac. Gen. Dev. Biol., 1:191-202.

Kelly, R.O., and J.F. Fallon 1981 The developing limb: An analysis of interacting cells and tissues in a model morphogenetic system. In: Morphogenesis and Pattern Formation T.G. Connelly, L. Brinkley and B. Carlson, eds. Raven Press, New York, pp. 49-85.

Lewis, C., L. Thibault, R. Pratt, and L. Brinkley 1980 An improved culture system for secondary palatal elevation. In Vitro, 16:453-460.

Nadol, J., J. Gibbins, and K. Porter 1969 A reinterpretation of the structure and the development of the basement lamella: An ordered array of collagen in fish skin. Dev. Biol., 20:304-331.

Singley, C.T., and M. Solursh 1980 The use of tannic acid for the ultrastructural visualization of hyaluronic acid Histochemistry, 65:93-102.

Singley, C.T., and M. Solursh 1981 The spatial distribution of hyaluronic acid and mesenchymal condensation in the embryonic chick wing. Dev. Biol., 84:102-120.

Slavkin, H.C. 1974 Embryonic tooth formation. A tool for developmental biology. In: Oral Science Reviews. A.H. Melcher and G.A. Zarb, eds. Munksgard, Copenhagen, pp. 1-136.

Walker, B.E., and B. Crain, Jr. 1960 Effects of hypervitaminosis A on palate development in two strains of mice. Am. J. Anat., 107:49-58.

Zimmerman, B., H.-J. Barrach, H.-J. Merker, and N. Hinz 1985 Basement membrane formation and lung cell differentiation in vitro. Eur. J. Cell Biol., 36:6673. 